\title{
IDENTIFICAÇÃO DE POLINIZADORAS PARA A CULTIVAR DE MACIEIRA DAIANE ${ }^{1}$
}

\author{
MARCUS VINÍCIUS KVITSCHAL ${ }^{2}$, FREDERICO DENARDI ${ }^{3}$, \\ FILIPE SCHMIDT SCHUH ${ }^{5}$, DANIELLE CAROLINE MANENTI ${ }^{5}$
}

RESUMO - A garantia de boas produções em pomares comerciais de macieira depende de uma polinização eficiente, que também está relacionada com a compatibilidade de pólen-estigma, com a coincidência de época de floração e com a capacidade de produção e de germinação de pólen. O objetivo deste estudo foi avaliar a eficiência de diferentes genótipos de macieira como polinizadores da cv. Daiane nas condições climáticas do meio-oeste de Santa Catarina. Plantas de 'Daiane' foram polinizadas a campo com pólen de diversas seleções e cultivares de macieira, com subsequente proteção dos cachos com sacos de papel, por 72 h. Consideraram-se a coincidência de época de floração, a adaptação climática, a taxa de germinação, a reação à mancha foliar de Glomerella, além da frutificação efetiva e do número de sementes por fruto induzido pelas polinizadoras avaliadas. Os tratamentos mais eficientes na polinização da cultivar de macieira Daiane foram as seleções 140/76 e 140/228, respectivamente, que são indicadas para utilização conjugada, visando à maior eficiência na polinização.

Termos para indexação: Malus domestica, polinização, maçã, autoincompatibilidade.

\section{IDENTIFICATION OF NEW POLLINAZER FOR DAIANE APPLE VARIETY}

ABSTRACT - Ensuring good production in apple orchards depends on efficient pollination, which is directly related to pollen-stigma compatibility, blooming time coincidence, high production and good germination capacity of pollen. The aim of this study was to evaluate the efficiency of different apple genotypes as pollinizers of 'Daiane' cv. at the climate of Middle-west of the state of Santa Catarina, Brazil. Apple trees of 'Daiane' cv. were pollinated in the field with several apple selections from the Apple Breeding Program of Epagri - Empresa de Pesquisa Agropecuária e Extensão Rural de Santa Catarina. Right after pollination, the flowering clusters were protected with paper bags for $72 \mathrm{~h}$ hours. It were considered the coincidence on blooming time, the climatic adaptation of the trees, the percentage of germination, the reaction to Gala Leaf Spot disease, as well as the fruit set and the number of seed per fruit induced by the pollinizers of this study. It was observed that the best pollinizers for 'Daiane' apple trees were the selections 140/76 and 140/228, respectively. Both selections are indicated to be used combined as pollinizers of 'Daiane'.

Index terms: Malus domestica, pollination, apple, self-incompatibility.

\section{INTRODUÇÃO}

As espécies do gênero Malus frequentemente são total ou parcialmente autoincompatíveis. O sistema de incompatibilidade genética da macieira é o gametofítico, e ocorre em função da presença de um gene multialélico denominado lócus-S (BROOTHAERTS et al., 2004). Se o alelo S presente no grão de pólen depositado sobre o estigma da flor for comum ao da planta receptora de pólen (planta feminina), o crescimento do tubo polínico é inibido no estilete da flor (SCHNEIDER et al., 2005). Em função dessa autoincompatibilidade genética, a autofecundação é rara em pomares de macieira.

A macieira é uma cultura dependente de polinização cruzada, exigindo a presença de plantas polinizadoras geneticamente compatíveis para que seja assegurada boa frutificação. Denardi e Stuker (2008) salientam que é necessária a formação de, pelo menos, uma semente em cada um dos cinco carpelos para assegurar a formação de frutos com simetria de formato e com desenvolvimento normal. As sementes estimulam o desenvolvimento do tecido mesocárpico em sua circunvizinhança e, portanto, um fruto com três sementes é assimétrico. O número de

\footnotetext{
${ }^{1}$ (Trabalho 251-12). Recebido em:13-09-2012. Aceito para publicação em: 14-02-2012.

${ }^{2}$ Eng. Agr., D.Sc. Pesquisador, Empresa de Pesquisa Agropecuária e Extensão Rural de Santa Catarina - Epagri, Rua Abílio Franco, 1500, C.P. 591, 89500-000, Caçador - Santa Catarina. E-mail: marcusvinicius@epagri.sc.gov.br

${ }^{3}$ Eng. Agr., M.Sc. Pesquisador, Empresa de Pesquisa Agropecuária e Extensão Rural de Santa Catarina - Epagri, Rua Abílio Franco, 1500, C.P. 591, 89500-000, Caçador - Santa Catarina. E-mail: denardi@epagri.sc.gov.br

${ }^{4}$ Estudante de graduação em Agronomia, bolsista Embrapa/Uva e Vinho, Universidade Alto Vale do Rio do Peixe - UNIARP, Rua Victor Baptista Adami, 800, C.P. 232, Centro, 89500-000, Caçador - Santa Catarina. E-mail: filipess_@hotmail.com

${ }^{5}$ Estudante de graduação em Agronomia, bolsista CNPq ITI-A, Universidade Alto Vale do Rio do Peixe - UNIARP, Rua Victor Baptista Adami, 800, C.P. 232, Centro, 89500-000, Caçador - Santa Catarina. E-mail: daniellecmanenti@hotmail.com
} 
sementes por fruto pode ser usado como parâmetro de avaliação do grau de compatibilidade genética entre cultivares de macieira (GALLETTA, 1983).

Além da compatibilidade genética, há outros fatores que precisam ser considerados na escolha da cultivar polinizadora por ocasião do planejamento para implantação de pomares de macieira. A coincidência de floração entre as cultivares produtora e polinizadora, a quantidade de pólen produzida pela polinizadora e a taxa de germinação desse pólen também são essenciais (PETRI, 2006). Conforme Schneider et al. (2005), uma cultivar polinizadora deve produzir pólen em abundância. Isso deve ser observado, especialmente quando se deseja plantar uma nova cultivar produtora, diferente das tradicionais 'Gala', 'Fuji' ou seus clones. A cv. Daiane foi lançada pela Epagri (Empresa de Pesquisa Agropecuária e Extensão Rural de Santa Catarina) em 1998, com o intuito de oferecer aos produtores nova opção de escalonamento de colheita de maçãs. A 'Daiane' tem período de maturação e colheita no intervalo entre os períodos de colheita das cultivares Gala e Fuji, é resistente à mancha foliar de Glomerella (MFG) e produz frutos de alta qualidade gustativa (FIORAVANÇO et al., 2011).

Embora a 'Granny Smith' e 'Sansa' apresentem boa coincidência de floração e, por isso, são as mais utilizadas como polinizadoras da 'Daiane', essas cultivares têm algumas limitações, tais como a falta de adaptação climática a algumas regiões produtoras de maçãs no Sul do Brasil e problemas de ordem fitossanitária (CAMILO; DENARDI, 2006).

O objetivo deste trabalho foi avaliar a eficiência na polinização da 'Daiane' por diferentes seleções de macieira desenvolvidas pelo melhoramento genético da Epagri/Caçador, comparadas à 'Sansa' e à 'Granny Smith' no meio-oeste catarinense.

\section{MATERIAL E MÉTODOS}

$\mathrm{O}$ presente estudo foi realizado em um pomar de 'Daiane', localizado em Caçador - SC, às coordenadas geográficas $26^{\circ} 49^{\prime} 07^{\prime}$ ' de latitude sul, 50 59'06" de longitude oeste e altitude média de $960 \mathrm{~m}$. O pomar apresentava idade de cinco anos, sendo as plantas da 'Daiane' enxertadas sobre o porta-enxerto M-7.

As polinizadoras avaliadas constituíram-se das seleções de macieira oriundas do programa de melhoramento genético da Epagri: 140/37, 140/76, 140/215, 140/216, 140/228, 140/279 e 140/513, bem como das cultivares-controle Sansa e Granny Smith As seleções de macieira utilizadas neste estudo estão identificadas com código experimental, mas deverão ter seus nomes alterados por ocasião da inscrição no Registro Nacional de Cultivares - RNC, em função de exigências legais do Ministério da Agricultura, Pecuária e Abastecimento - MAPA, relativo à nomenclatura de cultivares no Brasil. A escolha das polinizadoras (tratamentos) deu-se em função de resultados obtidos em avaliações prévias de fenologia da floração, escolhendo-se genótipos que apresentavam coincidência de período de floração com a 'Daiane' e das cultivares-controle em função de as mesmas já serem tecnicamente indicadas e utilizadas em pomares da 'Daiane' para este fim.

O pólen utilizado nos cruzamentos foi obtido a partir de flores coletadas a campo, no estágio de balão rosado, a fim de evitar contaminação com pólen estranho. No laboratório, foi realizada a retirada das anteras por leve fricção das flores apetaladas, em peneira metálica $\mathrm{n}^{\circ} 10$ (malha de $2 \mathrm{~mm}$ ), sobre placas de Petri. As anteras foram secas em estufa, sem circulação forçada de ar, sob temperatura constante de $25^{\circ} \mathrm{C}$, por período de 48 horas, e em seguida armazenadas em vidros levemente tampados com algodão, acondicionados em câmara de vácuo contendo sílica granulada, em geladeira, à temperatura aproximada de $5^{\circ} \mathrm{C}$.

Previamente à realização das polinizações, foram realizados testes de germinação do pólen de todos os tratamentos (polinizadoras da 'Daiane') utilizados. $\mathrm{O}$ teste de germinação foi realizado in vitro, em meio de cultura ágar-água (1\%), contendo $10 \%$ de açúcar e $10 \mathrm{mg} . \mathrm{L}^{-1}$ de ácido bórico, cuja metodologia constitui-se das seguintes etapas: inoculação do pólen com auxílio de pincel sobre meio de cultura em lâminas de vidro; acondicionamento das laminas em placas de Petri forradas com papeltoalha umedecido, tampadas e vedadas em seguida com plástico filme; incubação das placas em estufa a $25^{\circ} \mathrm{C}$, por um período de 3 a 4 horas; contagem dos grãos de pólen germinados e não germinados em microscópio óptico em três campos de visualização; a partir das contagens obtidas, calculou-se o percentual germinativo médio dos grãos de pólen de cada um dos tratamentos

O processo de polinização das flores da 'Daiane' foi realizado a campo e constitui-se das seguintes etapas: escolha e marcação de 150 a 170 flores em estágio de balão rosado por planta; emasculação destas, retirando-se as pétalas, as sépalas e os estames; polinização manual com o auxílio do dedo indicador, sempre esterilizado com álcool a $70 \%$, a cada mudança de genótipo polinizador. Em cada cacho floral, foram deixadas três flores, as quais foram protegidas com sacos 
de papel craft marrom logo após a polinização. A proteção dos cachos com saco de papel foi retirada 72 horas após a polinização ao final da tarde, evitando assim a visita de abelhas carregando pólen estranho. Como controle, foram utilizadas flores apenas emasculadas e, imediatamente, ensacadas com papel craft marron.

Também foi realizada inoculação artificial e avaliação da reação das seleções e cultivares quanto à mancha foliar de Glomerella-MFG (Colletotrichum gloeosporoides). Isso porque a 'Daiane' é resistente a esta doença, e o uso de polinizadoras com os mesmos atributos de resistência genética representa maior facilidade e menor custo no manejo fitossanitário dos pomares. A inoculação de MFG restringiuse às seleções que mostraram mais vantagens agronômicas para uso como polinizadoras da 'Daiane', considerando melhor desempenho, taxa de germinação de pólen, frutificação efetiva e produção de sementes nos frutos da 'Daiane'. A avaliação dos sintomas de MFG foi realizada sete dias após a inoculação, usando-se escala qualitativa de presença/ ausência de sintomas da doença, considerando-se que a herança dessa resistência é monogênica recessiva (KATSURAYAMA et al., 2001).

A fenologia floral foi avaliada de 2006 a 2008, considerando-se três diferentes fases da floração: início (aproximadamente $5 \%$ de flores abertas), plena (cerca de $70 \%$ das flores abertas) e final (a maioria das flores abertas e com as pétalas caídas).

Além da fenologia da floração, também foram avaliadas as seguintes características: 1) adaptação climática: feita mediante avaliação visual da brotação das plantas, usando-se escala de 1 a 5 , em que: 1 a 1,5 $=<20 \%, 2$ a $2,5=20$ a $50 \%, 3$ a $3,5=50$ a $70 \%, 4$ a $4,5=70$ a $90 \%$ e $5=>90 \%$ das gemas brotadas, após tratamento químico para a superação da dormência (óleo mineral a $4 \%$ + cianamida hidrogenada a $0,4 \%$ ); 2) porcentagem de germinação dos grãos de pólen; 3 ) frutificação efetiva: determinada mediante cálculo da porcentagem de frutos efetivamente fecundados e que estavam com desenvolvimento normal aos sete dias após a polinização; 4) número médio de sementes por fruto: determinado pelo cálculo da razão entre o total de sementes e o total de frutos obtidos em cada repetição, importante para determinar a viabilidade e a compatibilidade estilo-estigma; 5) reação à macha foliar de Glomerella - MFG.

O delineamento experimental foi em blocos ao acaso e constituiu-se de quatro (4) repetições. Cada repetição foi considerada uma planta, na qual foram polinizadas aproximadamente 150 a 170 flores. Os dados de frutificação efetiva e do número de sementes por fruto foram submetidos à analise de variância e aos testes de Scott-Knott e de Tukey, respectivamente $(\mathrm{P}<0,05)$.

\section{RESULTADOS E DISCUSSÃO}

Os dados fenológicos indicam que todas as seleções e cultivares-controle utilizadas apresentaram alguma coincidência com o espectro florífero da cv. Daiane (Tabela 1). Algumas iniciaram a floração antes, enquanto outras finalizaram a floração depois da 'Daiane'. As seleções 140/76, 140/216, 140/228, $140 / 279$, 140/513, bem como o controle 'Granny Smith'apresentaram amplo espectro florífero. Essa característica é importante por proporcionar aumento do período de disponibilidade de pólen da cultivar polinizadora para a cultivar produtora.

A seleção 140/76 foi a que apresentou melhor coincidência de floração, visto que seu período de floração foi bastante similar ao espectro florífero da 'Daiane'. No ano de 2007/2008, no entanto, a seleção 140/76 apresentou floração ligeiramente mais precoce e mais concentrada, coincidindo com o início do espectro florífero da 'Daiane'. A seleção 140/513 e a cultivar Granny Smith também mostraram coincidência em praticamente todo o espectro florífero da 'Daiane'. As seleções 140/228 e 140/216, por sua vez, mostraram amplo espectro de floração e melhor coincidência com o início de seu período florífero.

A seleção 140/279, embora tenha mostrado coincidência com o período de abertura das primeiras flores de 'Daiane', apresentou comportamento fenológico muito variável nos diferentes anos em que foi avaliada. Isso confere a ela um aspecto negativo, pois é extremamente importante que a polinizadora apresente estabilidade na coincidência de floração com a cultivar produtora ao longo dos anos (PETRI et al., 2008) e garanta sempre disponibilidade de pólen em todo o período de florescimento da cultivar produtora.

Quanto à adaptação climática (Tabela 2), a seleção 140/216 foi a que apresentou as maiores notas na escala de avaliação, mostrando-se mais bem adaptada às condições climáticas do meiooeste catarinense, com índice de brotação de gemas superior a $90 \%$. Por sua vez, apenas a 140/228 e a 'Sansa' apresentaram índices de brotação de gemas próximo de $50 \%$ (nota 3,0). As demais seleções mostraram melhor adaptação climática, recebendo nota 4,0 pela escala de brotação de gemas. Mas é importante ressaltar que as duas cultivarescontrole e todas as seleções apresentaram índices de adaptação, no mínimo, iguais à da 'Daiane', a qual vem mostrando boa resposta na indução 
química de superação da dormência nas principais regiões de cultivo da macieira no Sul do Brasil (FIORAVANÇO et al., 2011), produzindo com êxito na região de Fraiburgo-SC. Levando-se em conta apenas a adaptação climática e a resposta à indução da superação da dormência das plantas polinizadoras no pomar, que foram pelo menos iguais à resposta da cultivar produtora, qualquer um dos genótipos avaliados pode ser útil como polinizador da 'Daiane'.

A capacidade de germinação do pólen mostrou variação considerável (Tabela 2). Os melhores resultados de germinação do pólen foram observados nas seleções 140/228, 140/37, 140/216 e 140/76, todas com mais de $70 \%$ do pólen germinado. A seleção 140/279 indicou que a qualidade de seu pólen pode ser não satisfatória, dada a baixa taxa de germinação $(4,7 \%)$ verificada nos testes in vitro. Conforme Keulemans et al. (1994), taxas de germinação de pólen acima de $30 \%$ são suficientes para assegurar boa fertilização e boa frutificação efetiva. Assim, dentre os genótipos estudados, apenas as seleções 140/279, 140/513 e 140/215 não produziram pólen com taxa de germinação satisfatória.

Neste trabalho, também se verificou que todos os genótipos testados propiciaram índices de frutificação efetiva satisfatórios para a cultivar Daiane. Kozma et al. (2003) salientam que, para se obter bons níveis de produtividade de maçãs em pomares cultivados sob alta densidade, necessita-se atingir níveis de frutificação efetiva de, pelo menos, $15 \%$ a $20 \%$, dependendo da intensidade da floração da cultivar produtora. A variação nas médias de frutificação efetiva da 'Daiane' quando polinizada pelos diferentes genótipos foi significativa $(\mathrm{P}<0,05)$, com destaque para a seleção $140 / 76$, seguida da 140/228, ambas propiciando médias de frutificação efetiva acima de $40 \%$ (Tabela 2 ).

O número de sementes por fruto da 'Daiane' também evidenciou variação significativa $(\mathrm{P}<0,05)$ entre os tratamentos, embora todos tenham formado cinco sementes por fruto. O número de sementes por fruto é importante para assegurar o desenvolvimento simétrico destes, pois em geral frutos com pequeno número de sementes ficam deformados (DENARDI; STUKER, 2008), de menor tamanho e mais suscetíveis à formação de "russeting" (GALLETTA, 1983). Ademais, o elevado número de sementes por fruto observado neste estudo é indicativo de boa compatibilidade genética pólen-estigma entre os genótipos testados e a cultivar Daiane (GALLETA, 1983).

A 'Daiane' não apresentou ocorrência de partenocarpia, bem como de autofecundação. Isto é confirmado pela ausência de produção de frutos nos cachos florais não polinizados e protegidos com sacos de papel (Tabela 2). Assim, os resultados de frutificação efetiva e de número de sementes por fruto observados na 'Daiane' polinizada por cada um dos genótipos polinizadores testados, resultaram da efetiva polinização destes, e não de eventual ocorrência de autofecundação ou partenocarpia, o que também demonstra que é inviável o cultivo da 'Daiane' sem a presença de plantas polinizadoras.

Além dos aspectos agronômicos e botânicos, também são considerados os aspectos fitossanitários na avaliação e indicação de polinizadoras em macieira. É importante que exista mesmo padrão de reação às principais doenças entre a cultivar produtora e as respectivas polinizadoras. Dado que a 'Daiane' é resistente à mancha foliar de Glomerella (MFG), uma das doenças mais graves presentes nos pomares de macieira no Sul do Brasil, é importante que a cultivar polinizadora também tenha tal atributo para se evitar tratamento fitossanitário diferenciado entre as plantas da cultivar produtora e da polinizadora. Os testes de inoculação artificial de MFG mostraram que todas as seleções testadas são resistentes a esta doença. Das cultivares-controle, a Sansa mostrou reação de resistência, enquanto a 'Granny Smith' foi caracterizada como suscetível à MFG (Tabela 2) demonstrando, assim, desvantagem agronômica em relação às demais polinizadoras avaliadas.

Considerando todas as características avaliadas (Tabelas 1 e 2), a melhor polinizadora para a 'Daiane' foi a seleção 140/76, por apresentar boa coincidência de floração, boa adaptação climática (mais de $70 \%$ de gemas brotadas), alta porcentagem de germinação de pólen, resistência à MFG, além de ter induzido elevada frutificação efetiva e grande número de sementes por fruto na 'Daiane'. A alta frutificação efetiva e o elevado número de sementes por fruto sugerem que esta seleção apresenta boa compatibilidade gametofítica com a 'Daiane'. A seleção 140/228 também se mostrou bastante eficiente na polinização da 'Daiane', embora sua época de floração tenha-se mostrado um pouco precoce. Por outro lado, ressalta-se que a amplitude de floração desta seleção é bastante elevada, iniciando desde 20 dias antes e estendendo-se até quase o final da floração da 'Daiane' (Tabela 1).

A conjugação das seleções 140/76 e 140/228 constitui-se de uma boa estratégia para a polinização da cv. Daiane, dado que a seleção 140/228 assegura a polinização de flores, desde o início da florada até a plena floração da 'Daiane', enquanto a seleção 140/76 tem grande potencial de polinização durante todo o espectro florífero dessa cultivar. Tal combinação garante um espectro de disponibilidade de pólen 
viável durante todo o período de florescimento da 'Daiane', o que aumenta significativamente a chance de se obter boas produções mesmo sob condições ambientais subótimas (SCHNEIDER et al., 2005).
Nessa situação, sugere-se adotar, pelo menos, $15 \%$ de plantas polinizadoras, bem distribuídas no pomar, proporção ligeiramente maior que a recomendada normalmente, que é de $10 \%$ (PETRI, 2006).

TABELA 1 - Fenologia de seleções e cultivares de macieira em três anos de observação, Epagri / Estação Experimental de Caçador. 2006 a 2009.

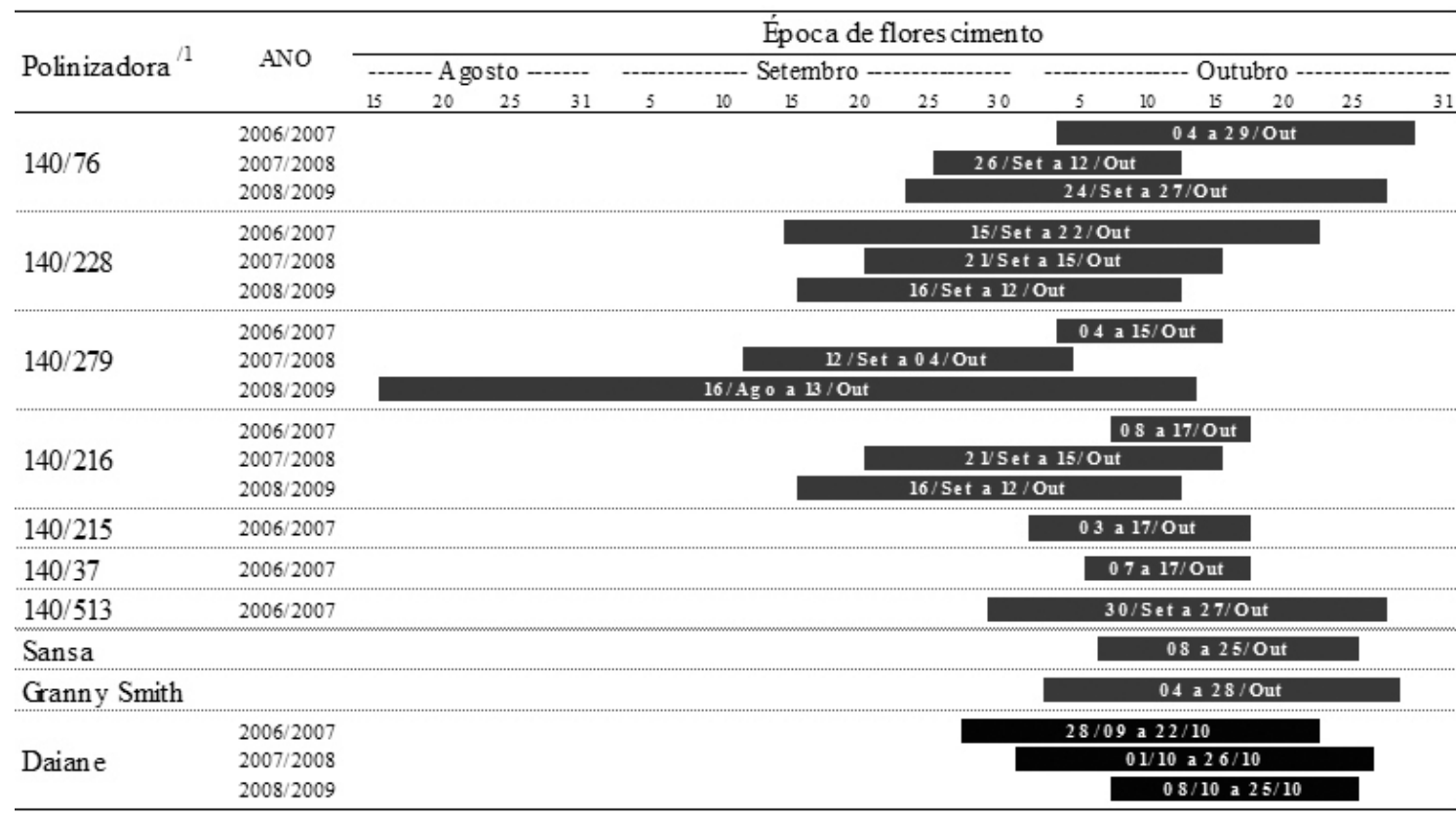

${ }^{/ 1}$ As seleções 140/215, 140/37, 140/513 foram avaliadas somente no primeiro ano, em função de não terem apresentado bons resultados de polinização em avaliações preliminares; A fenologia da Sansa e da Granny Smith é apresentada por períodos médios, visto ser cultivares tradicionais usadas como polinizadoras nos pomares de macieira do Sul do Brasil e com épocas de florescimento bem conhecidas.

TABELA 2 - Adaptação climática, percentagens de germinação do pólen, frutificação efetiva, número de sementes por fruto e reação à mancha foliar de Glomerella (MFG),nas cultivares e seleções de macieira - Epagri / Estação Experimental de Caçador, Caçador, 2006/2007.

\begin{tabular}{lccccc}
\hline Polinizadora & $\begin{array}{c}\text { Adaptação } \\
\text { climática }^{/ 1}\end{array}$ & $\begin{array}{c}\% \text { Germinação de } \\
\text { pólen }^{/ 2}\end{array}$ & $\begin{array}{c}\text { Frutificação } \\
\text { Efetiva }^{/ 3}\end{array}$ & $\begin{array}{c}\mathrm{N}^{\text {o }} \text { sementes } \\
\text { por fruto }^{/ 4}\end{array}$ & $\begin{array}{c}\text { Reação à } \\
\text { MFG }\end{array}$ \\
\hline $140 / 76$ & 4,0 & 71,6 & $44,5 \mathrm{a}$ & $6,4 \mathrm{ab}$ & $\mathrm{R}$ \\
$140 / 228$ & 3,0 & 79,0 & $41,0 \mathrm{~b}$ & $7,1 \mathrm{a}$ & $\mathrm{R}$ \\
$140 / 279$ & 4,0 & 4,7 & $36,5 \mathrm{c}$ & $5,6 \mathrm{~b}$ & $\mathrm{R}$ \\
$140 / 215^{/ 5}$ & 4,0 & 26,7 & $35,8 \mathrm{c}$ & $6,4 \mathrm{ab}$ & \\
$140 / 216$ & 4,5 & 72,7 & $30,4 \mathrm{~d}$ & $6,4 \mathrm{ab}$ & $\mathrm{R}$ \\
$140 / 37^{/ 5}$ & 4,0 & 76,4 & $26,5 \mathrm{e}$ & $6,6 \mathrm{ab}$ & \\
$140 / 513^{/ 5}$ & 4,0 & 13,0 & $26,3 \mathrm{e}$ & $6,1 \mathrm{ab}$ & \\
\hline Sansa & 3,0 & 33,5 & $24,6 \mathrm{e}$ & $6,8 \mathrm{ab}$ & $\mathrm{R}$ \\
Granny Smith & 3,5 & 32,8 & $13,8 \mathrm{f}$ & $6,9 \mathrm{a}$ & $\mathrm{S}$ \\
Daiane & 3,0 & --- & 0,0 & 0,0 & $\mathrm{R}$ \\
\hline
\end{tabular}

${ }^{/ 1}$ Escala de adaptação climática: 1 a $1,5=<20 \% ; 2$ a 2,5=20 a $50 \% ; 3$ a 3,5=50 a $70 \% ; 4$ a 4,5=70 a $90 \% ; 5=>90 \%$ de gemas brotadas; ${ }^{2}$ Sob condição de cultivo in vitro; ${ }^{13}$ Médias seguidas pela mesma letra, na coluna, não diferem significativamente (P $\geq 0,05$ ), pelo teste de Tukey; ${ }^{/ 5}$ Seleções não inoculadas por não terem mostrado bons resultados de polinização em fases preliminares do estudo $(\mathrm{R}=$ Resistente; $\mathrm{S}=$ Suscetível). 


\section{CONCLUSÕES}

1-Todas as seleções de macieira testadas mostram-se geneticamente compatíveis com a cultivar de macieira Daiane.

2-Para a polinização da cultivar de macieira Daiane, as seleções 140/76 e 140/228 são as que apresentam melhor resposta.

\section{AGRADECIMENTOS}

Os autores agradecem à Embrapa, à Fapesc e ao $\mathrm{CNPq}$, pelo apoio financeiro durante a realização deste estudo. Agradecem também ao pesquisador Dr. Walter Ferreira Becker e à bolsista Alana Karine Baldicera, pelo auxílio prestado nas avaliações de reação genética dos genótipos ao fungo da mancha foliar de Glomerella.

\section{REFERÊNCIAS}

BROOTHAERTS, W.; VAN NERUM, I.; KEULEMANS, J. Update on and review of the incompatibility (S-) genotypes of apple cultivars. HortScience, Alexandria, v.39, n.5, p.943-947, 2004.

CAMILO, A.P.; DENARDI, F. Cultivares: Descrição e comportamento no Sul do Brasil. In: Epagri. A cultura da macieira. Florianópolis: GMC/Epagri, 2006. p.113-168.

DENARDI, F.; STUKER, H. Eficiência de diferentes cultivares de macieira como polinizadoras da 'Castel Gala' e da 'Condessa'. Agropecuária Catarinense, Florianópolis, v.21, n.1, p.79-83, 2008.

FIORAVANÇO, J.C.; DENARDI, F.; CZERMAINSKI, A.B.C.; KVITSCHAL, M.V.; OLIVEIRA, P.R.D. Avaliação da cultivar de macieira Daiane em Vacaria-RS. Bento Gonçalves: Embrapa/Uva e Vinho, 2011. 8p. (Comunicado Técnico 109).
GALLETTA, G.J. Pollen and seed management. In: MOORE, J.N.; JANICK, J. Methods in fruit breeding. West Lafayette: Purdue University Press, 1983. p.23-47.

KATSURAYAMA, Y.; BONETI, J.I.S; BECKER, W.F.; OZAWA, T.; TSUCHIYDA, S. Resultados recentes sobre a epidemiologia da Mancha da Gala. In: ENCONTRO NACIONAL SOBRE FRUTICULTURA DE CLIMA TEMPERADO ENFRUTE, 4., 2001, Fraiburgo. Anais..., Caçador: Epagri, 2001. p.80-88.

KEULEMANS, J.; EYSSEN, R.; COLDA, G. Improvement of seed act and seed germination in apple. In: SCHMIDT, H.; KELLERHALS, M. Progress in temperate fruit breeding. Dordrecht: Netherlands Kluwer Academic, 1994. p.225-228.

KOZMA, P.; NYÉRI, J.; SOLTÉSZ, M. Floral biology, pollination and fertilization in temperate zone fruit species and grape. Budapest: Akadémiai Kiadó, 2003. 621p.

PETRI, J.L. Formação de flores, polinização e fertilização. In: Epagri. A cultura da macieira. Florianópolis: GMC/Epagri, 2006. p.229-260.

PETRI, J.L.; HAWERROTH, F.J.; LEITE, G.B. Fenologia de espécies silvestres de macieira com polinizadoras das cultivares Gala e Fuji. Revista Brasileira de Fruticultura, Jaboticabal, v.30, n.4, p.868-874, 2008.

SCHNEIDER, D.; STERN, R.A.; GOLDWAY, M. A comparison between semi- and fully compatible apple pollinators grown under subotptimal pollination conditions. HortScience, Alexandria, v.40, n.5, p.1280-1282, 2005. 